\title{
Impacts of a University-led, On-demand Sounding Program on Human and Numerical Weather Prediction Model Forecasts in an Upper-air Observation Hole
}

\author{
MARK D. BENOIT, CHRISTOPHER J. NOWOTARSKI, DON T. CONLEE \\ Texas A\&M University, College Station, Texas \\ LANCE WOOD \\ NOAA/NWS, League City, Texas
}

(Manuscript received 14 May 2018; review completed 15 August 2018)

\begin{abstract}
This paper describes the forecasting impacts of a partnership between university faculty and students and forecasters in an on-demand supplemental radiosonde observations program in a data-sparse region. Impacts of the supplemental radiosondes and incorporation into forecast practices by forecasters in both severe convective weather and winter precipitation scenarios are described, with considerable influence found in both situations. Results of a data assimilation experiment, wherein the supplemental radiosondes are assimilated into highresolution, convection-allowing regional numerical weather prediction model forecasts are also presented. Although assimilation of the radiosonde has limited results in model forecast skill in convective precipitation events, modest forecast improvements are found in short-range forecasts of low-level temperatures during winter weather events.
\end{abstract}

\section{Introduction}

Operational upper-air observations by radiosonde (RAOBs) are relatively sparse both spatially and temporally across the continental United States with standard observing times only twice daily at $<100$ stations. Even though operational sites often launch special radiosondes at non-standard times during highimpact weather events, forecasts for areas far from operational launch sites (i.e., in observation "holes") often suffer from a paucity of upper-air observations during critical times. One such location is College Station, Texas (CLL), which is $>150 \mathrm{~km}$ away from the nearest radiosonde sites in Fort Worth, Corpus Christi, Del Rio, Shreveport, and Lake Charles (Fig. 1). In recognition of this data gap, faculty and students in the Department of Atmospheric Sciences at Texas A\&M University in College Station, Texas have been engaged in an adaptive supplemental upper-air observation program called the Student Operational Upper-air
Program (SOUP), which launches on-demand special RAOBs from the campus of Texas A\&M University in College Station, Texas (CLL) on the request of local and national forecasters, and in the course of educational training.

Although special CLL RAOBs have been of use to National Weather Service (NWS) and Storm Prediction Center (SPC) forecasters (among others) in short-term forecasts and nowcasts of severe convective weather and winter precipitation events, it is also possible that assimilation of additional RAOBs in data-sparse regions may improve high-resolution, convectionallowing numerical weather prediction models. RAOBs have been shown to have a positive impact on shortrange model forecasts in operational forecast models (e.g., Benjamin et al. 2010), and studies suggest that assimilation of targeted observations may add skill to some forecasts (e.g., Langland 2005; Kelly et al. 2007; Gelaro et al. 2010). Thus, we hypothesize that assimilation of CLL special RAOBs into high- 


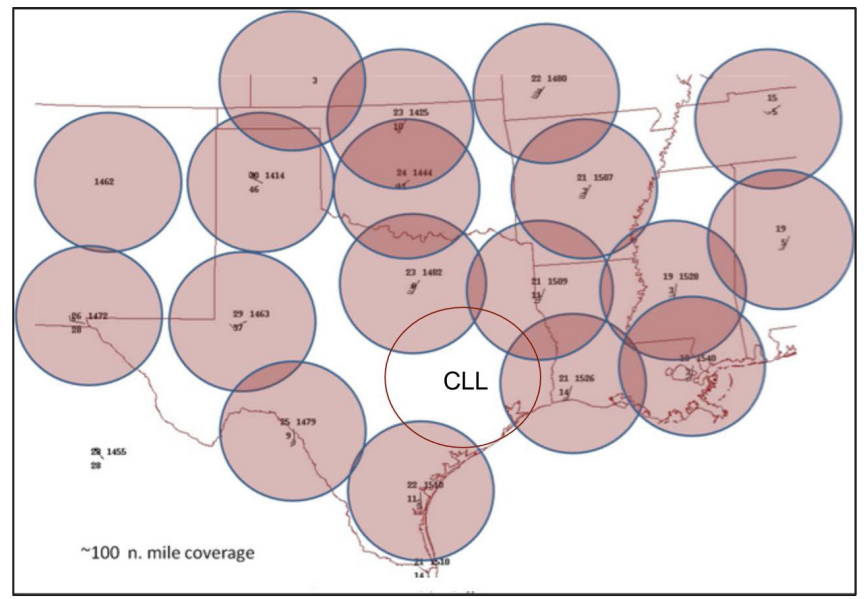

Figure 1. Upper-air observation hole over Central Texas showing the location of the special sounding site, College Station, TX (CLL). Circles represent 150$\mathrm{km}$ ( $\sim 100$ nautical mile) range rings from standard radiosonde launch sites (shaded) and the Texas A\&M Launch Site in College Station, TX (CLL). Click image for an external version; this applies to all figures and tables hereafter.

resolution, convection-allowing model forecasts will improve skill, especially in the absence of direct assimilation of other observations.

This paper describes the impacts of special radiosonde observations on both the operational forecast process and numerical weather prediction. Section 2 describes the usefulness to various forecasters in both severe convective and winter environments. Section 3 describes the data, methods, and results of an experiment wherein special radiosonde observations were assimilated into experimental high-resolution Weather Research and Forecasting (WRF) forecasts. Finally, conclusions and discussion of the future potential of such university-forecaster partnerships are described in Section 4.

\section{Impacts on human forecasting decisions}

More than 40 supplemental, on-demand CLL RAOB launches have been performed in high-impact weather events since 2011. The majority of launches are requested by the Houston/Galveston WFO (HGX), though several launches have been requested by the San Antonio/Austin (EWX) and Dallas/Fort Worth (FWD) WFOs as well as the Storm Prediction Center (SPC). Of these requests, approximately $80 \%$ were for severe convective storm events, while the remaining $20 \%$ have been for winter events with the potential for frozen/ freezing precipitation. Launches have been requested at nearly all times of day, though the majority occurred in the afternoon and evening hours (1800-0000 UTC; Fig. 2). In addition to NWS offices and centers, the data are disseminated widely to broadcast and private meteorologists for their use. Although quantifying the impact of this is difficult, anecdotally, it was very well received and often re-distributed with added commentary. As such, a rather large distribution list of regional and national partners has evolved over time.

Soundings requested on days of severe thunderstorm potential often had influence on both local [HGX, EWX, FWD, and the Houston Center Weather Service Unit (ZHU)] and national forecasters (SPC). CLL RAOBS were often referenced as part of mesoscale environmental analysis area forecast discussions at the local WFOs and in mesoscale forecast discussions and outlooks by the SPC (Fig. 3). Several soundings directly affected convective watch timing decisions and convective outlook updates from the SPC. A sounding from 0600 UTC on 10 February 2013 (Fig. 4a) was useful in issuing a tornado watch (Fig. 4b) the following morning:

"The 0600 UTC CLL sounding confirmed for us that the favorable environment did indeed extend at least as far northeast as east central Texas, and that the moist boundary layer was even more supportive of sustained updraft development there than it was farther west.... The sounding also suggested that, given the expected absence of strong low- or mid-

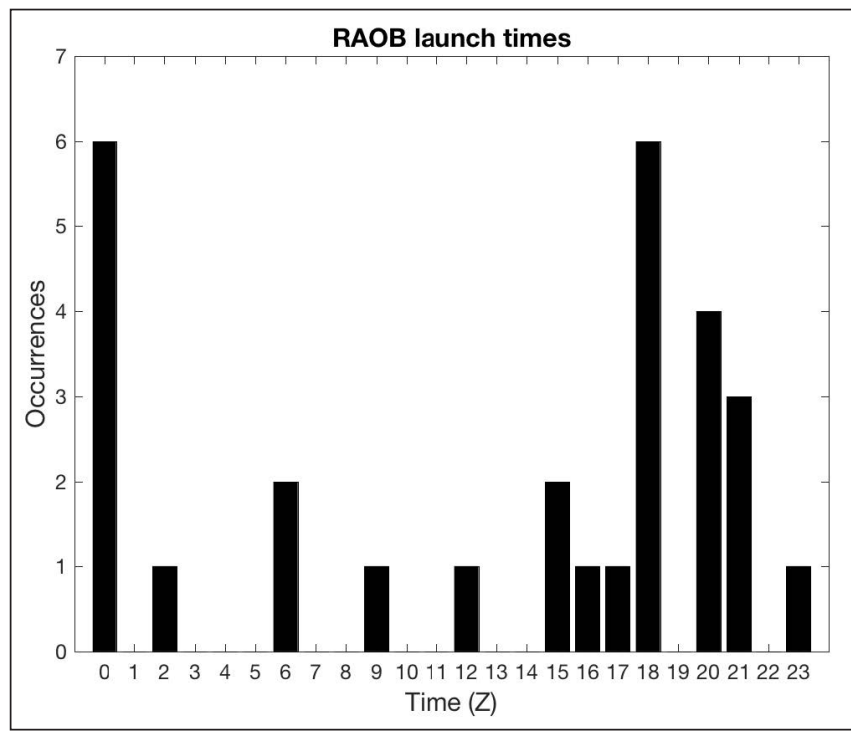

Figure 2. Histogram showing the frequency of CLL RAOB launch times for cases in this study. 


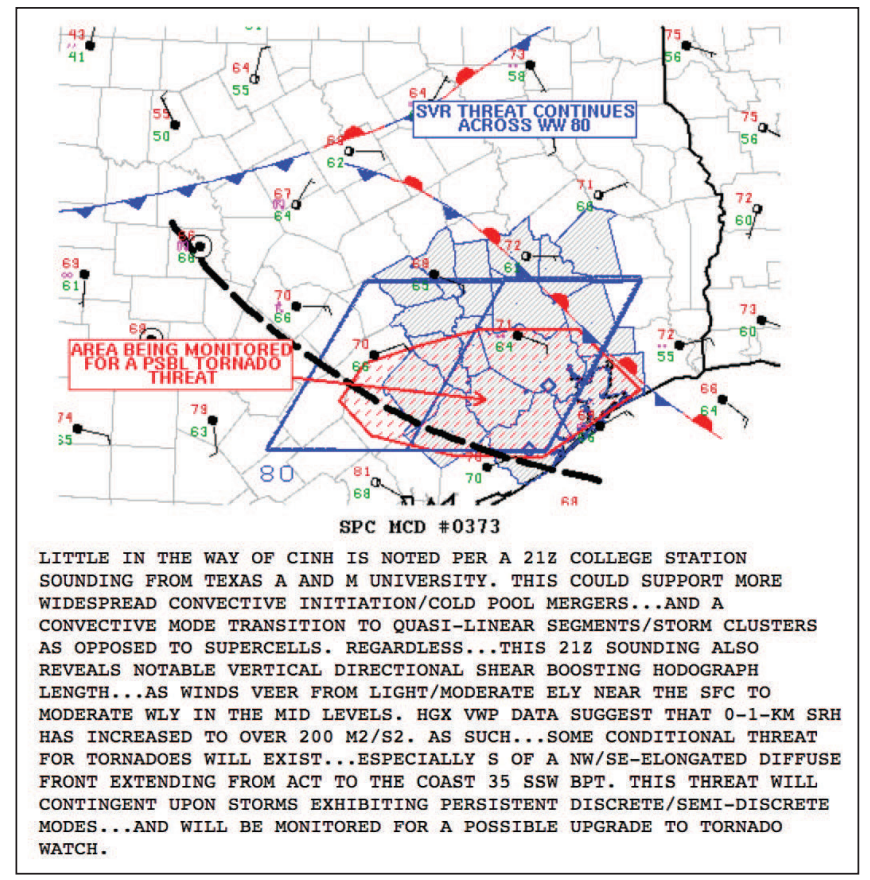

Figure 3. Graphic and discussion highlighting the utility of an on-demand CLL RAOB launched at $21 \mathrm{Z}$ on 2 April 2013 from SPC Mesoscale Discussion \#373 issued at 2200 UTC on 2 April 2013.

level forcing for ascent over the middle Texas coastal plain, the likelihood for additional storm development south of the developing ones was minimal. As a result, we were able to correctly issue a narrow, elongated watch that minimized false alarm area." (S. Corfidi, SPC lead forecaster, personal communication).

Local forecasters at HGX and ZHU used a 2100 UTC 3 April 2014 special CLL RAOB to help assess thunderstorm potential in preparation of the CLL and Houston George Bush Intercontinental Airport (IAH) terminal aerodrome forecasts (TAFs), finding a combination of the RAOB and ACARS data was useful in diagnosing erosion of the midlevel cap in conjunction with convection allowing model forecasts.

Though less frequent than their severe convective counterparts, winter weather RAOB launches were also of considerable use to forecasters. Much of this impact stems from the fact that central/southeast Texas is often on the edge of winter weather impacts, where predicting changeover of precipitation type can be especially challenging. Forecasters often struggle with projecting the precipitation type due to marginal conditions that are dependent on accurate observations of the exact thermodynamic profile. On 8 December 2013, a
0000 UTC supplemental sounding (Fig. 5) led to the issuance of a winter weather advisory approximately an hour earlier than originally anticipated. There was a broad area of low reflectivity on area radars and surface temperatures were hovering near freezing. The sounding matched up well with some of the model data and confirmed the earlier thinking of precipitation type: freezing drizzle or rain. The sounding gave HGX forecasters confidence concerning the issuance of an advisory because freezing drizzle/rain would likely occur soon given the sounding's depiction of the lowlevel thermodynamic profile. Without the sounding, HGX forecasters indicated that they would have waited longer to issue an advisory pending ground confirmation that icing was actually occurring. Thus, the special
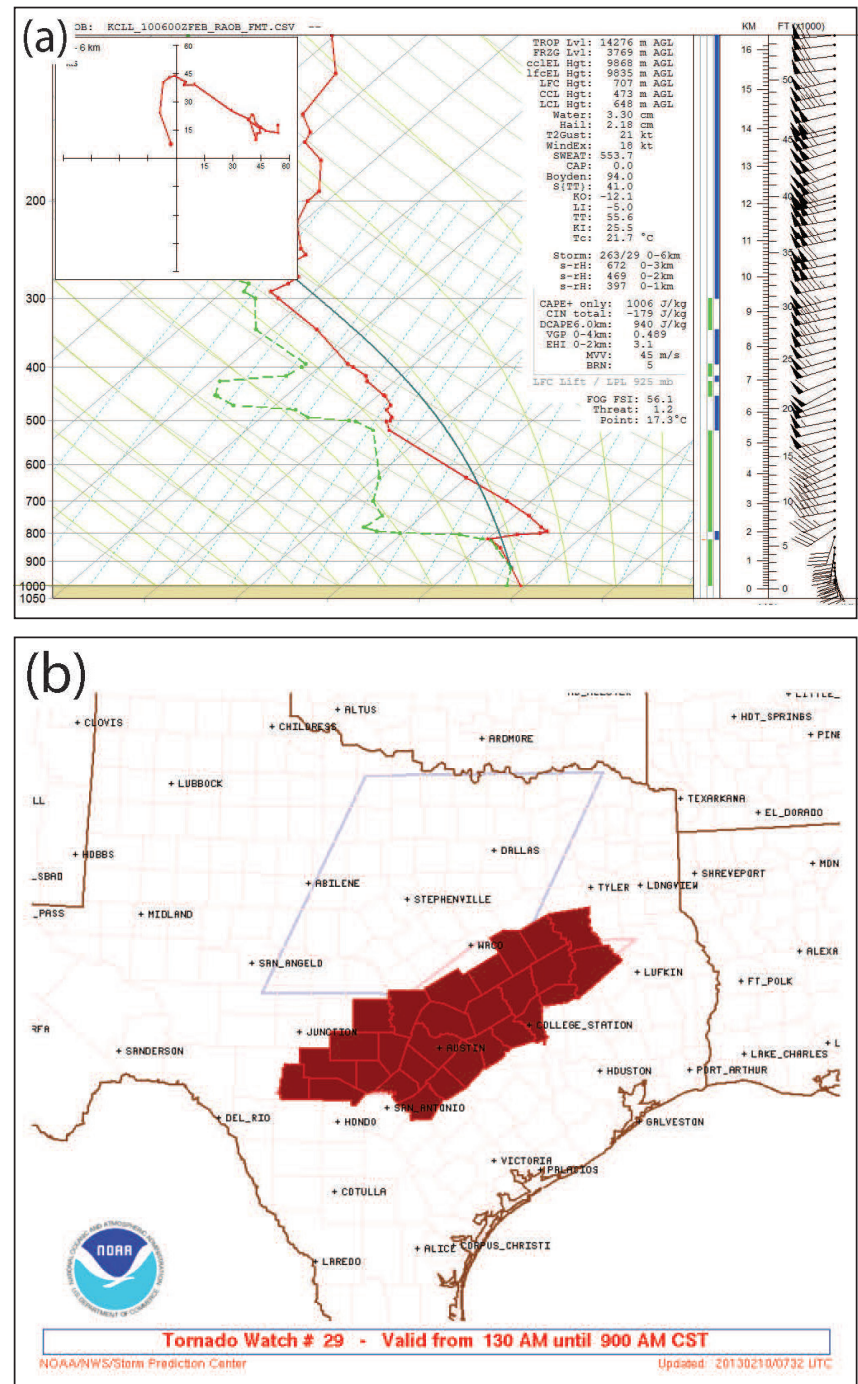

Figure 4. (a) On-demand CLL RAOB from 0600 UTC on 10 February 2013 that influenced the issuance of (b) SPC tornado watch \#29 on 10 February 2013. 


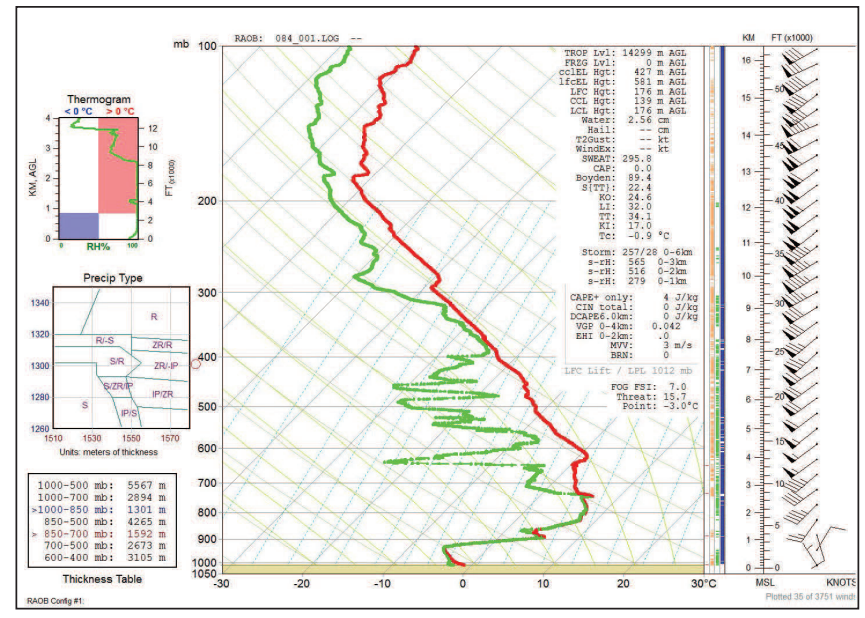

Figure 5. 0000 UTC CLL special RAOB on 8 December 2013 showing potential for freezing drizzle/rain.

RAOB prevented a negative lead time on the advisory. On another occasion, a special winter RAOB notably assisted EWX forecasters:

"The 0000 UTC 24 January 2014 supplemental sounding helped diagnose the potential for freezing/ frozen precipitation across south central and southeast Texas. The sounding clearly showed a profile supportive of freezing rain/drizzle with a significant, saturated elevated warm layer, with the surface temperature below freezing. This knowledge helped confirm that freezing rain/drizzle would be the predominant precipitation (instead of sleet or snow).... With nearby sounding sites being $>150 \mathrm{~km}$ away, the special sounding was critical in identifying the icing potential and helping confirm model forecast solutions for the succeeding 6-12 hours." (J. Zeitler, EWX Science and Operations Officer, personal communication)

The Houston CWSU also found several launches beneficial for assessing area icing conditions affecting aircraft. For example, the 1900 UTC sounding on 18 October 2013 showed significant drying between 12 and $13 \mathrm{kft}$; therefore, aircraft only experienced light rime icing as opposed to the perceived potential of moderate icing.

The student expertise gained through on-demand RAOB launches as part of the TAMU SOUP program was also leveraged in mobile operations as part of the 2012 National Severe Storms Laboratory (NSSL) Hazardous Weather Testbed (HWT) Spring Experiment. Numerous launches were made during the experiment, including successive launches to examine boundary layer evolution (Coniglio et al. 2013). Moreover, data collected from this experience allowed for simultaneous use of International Meteorology Systems (InterMet) and Vaisala systems in the 2013 Mesoscale Predictability Experiment (MPEX; Weisman et al. 2015), in which the TAMU SOUP team participated. Data collected by TAMU SOUP were included in several publications resulting from that project (e.g., Trapp et al. 2016; Kerr et al. 2017; Trapp and Woznicki 2017).

\section{Impacts on numerical weather prediction (NWP) through data assimilation}

We hypothesize that, just as these RAOBs are useful to forecasters in a data-sparse upper-air region, there is potential value to NWP, particularly in a high-resolution, convection-allowing model. RAOBs are an important component of data assimilated into global and regional models, which generally serve as the initial and boundary conditions for nested finerresolution $(<10 \mathrm{~km}$ grid spacing) simulations. To test the impact of a single RAOB in a data-sparse region, we assimilate special RAOBs launched at CLL into convection-allowing regional WRF simulations. These simulations are compared with simulations initialized without assimilation of the special RAOBs. To test the model sensitivity to the RAOB when a diverse array of other observations are assimilated, two other sets of simulations are performed for each case, where observations from the Meteorological Assimilation and Data Ingest System (MADIS) are assimilated with and without the special RAOB. Thus for each case, four simulations are compared and named as follows:

WRF_C: Initialized with initial and boundary conditions from the North American Model (NAM) $12-\mathrm{km}$ model with no additional data assimilation

WRF_R: Only the specialCLLRAOB is assimilated into WRF_C

WRF_OB: MADIS observations are assimilated into WRF_C

WRF_OBR: MADIS observations and the special CLL RAOB are assimilated into WRF_C

Each model forecast is compared against the relevant Real Time Mesoscale Analysis (RTMA) and Rapid Refresh (RAP) analysis, which are treated as the true 
atmospheric state for verification purposes.

\section{a. Methods}

All radiosondes launched at Texas A\&M were International Meteorology Systems (Inter-Met) iMet1 radiosondes. Each radiosonde contains a glass bead thermistor for fast response temperature, a thin-film capacitor for relative humidity measurements ${ }^{1}$, a pressure sensor, and a 12-channel GPS receiver for obtaining height, wind direction, and wind speed (based on radiosonde drift). Data from 29 total launches were used, with 23 in spring, summer, and fall months for convective storm cases, and six in winter months for potential frozen/freezing precipitation cases. Launch time varied based on the needs of the particular forecasting scenario, but most launches occurred during the late morning to early evening hours (Fig. 2). Geopotential height measurements may be obtained using two methods from the raw radiosonde data. First, the pressure measured directly from the radiosonde is coupled with temperature and humidity measurements to obtain the geopotential height through the hypsometric equation. The iMet- 1 has a variable pressure offset of $-0.65 \mathrm{hPa}$ at an altitude of $26 \mathrm{~km}$ (Stauffer et al. 2013). If a pressure bias of $0.4 \mathrm{hPa}+/-$ $0.2 \mathrm{hPa}$ is assumed above $20 \mathrm{~km}$ for a radiosonde, the associated geopotential height difference would be 42 $+/-24 \mathrm{~m}$ using this method (Inai et al. 2015).

Conversely, the second and more commonly used contemporary method uses the GPS altitude coupled with temperature and humidity measurements to calculate the pressure (still via the hypsometric equation). The second method has allowed radiosonde manufacturers to eliminate pressure sensors from their radiosondes, so long as an accurate surface pressure is obtained concurrent with the radiosonde launch. Poor GPS reception, temperature, and humidity measurements may all affect the calculations of pressure through this method, but Inai et al. (2009) showed the second method tends to be more accurate. Comparisons between methods were performed for the cases included in this study, also finding that the second method is more accurate. Thus, based on these results and the widespread use of the GPS method, pressures are calculated at GPS heights rather than the former method.

${ }^{1}$ Several radiosondes used in this study had larger capacitors, but the majority used thin-film capacitors.
Inasmuch as model forecast sensitivity to assimilation of radiosonde data is the main subject of this research, simulations are also performed where additional observations are assimilated. MADIS is the source of these observations, which is composed of observations through NOAA and other providers such as departments of transportation, universities, volunteers, and the private sector. These include Automated Surface Observation Systems (ASOS), Automated Weather Observation Systems (AWOS), Surface Aviation Observations (SAO), aircraft vertical profiles (AirReps), mesonet observations, maritime observations, standard RAOBs, NOAA profiler networks (NPN), multiple agency profilers (MAP), and satellite wind observations using IR and visible channels. MADIS data undergo an extensive quality control procedure (Miller et al. 2005) before they are available for data assimilation. Although many poorquality observations are eliminated through this process and the data assimilation scheme, some may still have a negative influence on the model analysis. Indeed, for a limited number of cases, we tested the forecast sensitivity to the removal of observations with generally higher standard errors (mesonet observations, satellite winds, and profilers).

All forecasts are performed with the WRF model with the Advanced Research WRF (ARW) core, version 3.6 (Skamarock et al. 2008). The governing equations are compressible, non-hydrostatic flux-form Euler equations with a sigma vertical coordinate system. For all forecasts, the model is run over a 425 x 425 grid point horizontal domain with $3-\mathrm{km}$ horizontal grid spacing centered over the south-central United States (Fig. 6). There are 40 vertical levels to an upper pressure of $50 \mathrm{hPa}$. The large model time step is $18 \mathrm{sec}$ and each simulation is run for $24 \mathrm{~h}$ beyond the initial data assimilation (DA) cycling. First guess/initial conditions and boundary conditions are obtained from the NAM 12-km grid forecast.

Model performance is often sensitive to choices in parameterization of subgrid-scale processes; however, this sensitivity is not the focus of this study. Therefore, all simulations are performed with identical parameterization schemes. The Mellor-YamadaNakanishi-Niino (MYNN; Nakanishi and Niino 2004, 2009) planetary boundary layer (PBL) scheme is used as prior research has shown it performs well in convection-allowing forecasts in similar scenarios to our convective cases (Coniglio et al. 2013). The Thompson single-moment bulk microphysics parameterization 


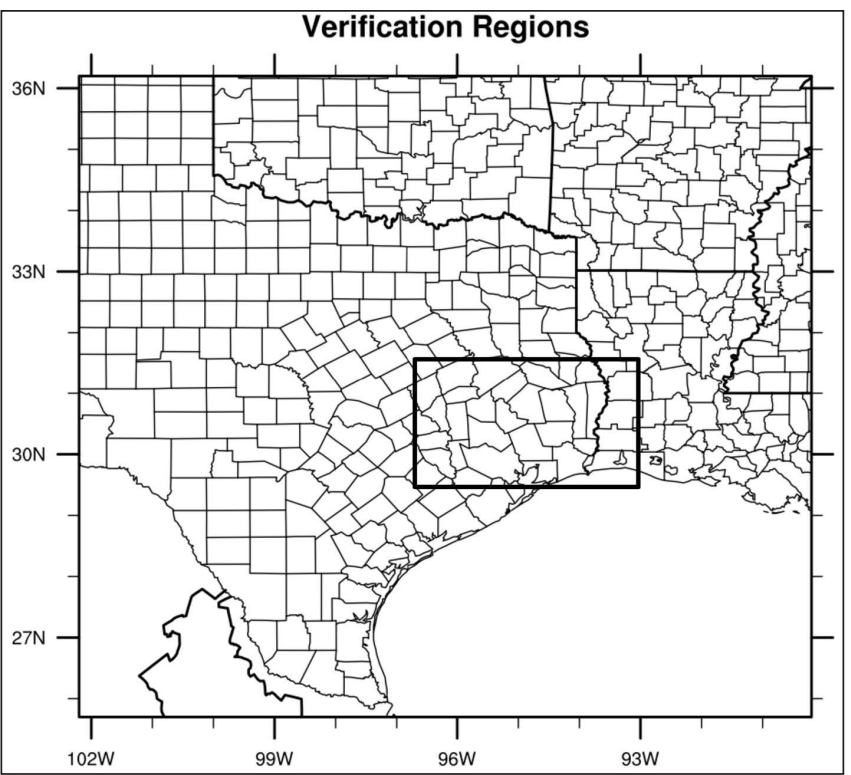

Figure 6. Full model domain (outer box) and inner box showing smaller verification region near and downstream of CLL RAOB launch site.

(Thompson et al. 2008) is used. The land surface is parameterized using the five-layer Noah land surface model (Chen and Dudhia 2001; Ek et al. 2003). Both short- and long-wave radiation is parameterized using the Rapid Radiative Transfer Model with trace Gases (RRTRMG; Iacono et al. 2008). No sub-grid scale convective parameterization is employed as convection is assumed to be explicitly resolved with 3-km horizontal grid spacing.

Data assimilation is performed using the WRF Data Assimilation System (WRFDA; Barker et al. 2012) version 3.6 in a 3DVAR configuration. Though more advanced DA systems exist (e.g., Ensemble Kalman Filter, 4DVAR, hybrid methods), we chose 3DVAR for its computational efficiency and widespread use for regional modeling. Though model forecasts can be highly sensitive to the configuration of the DA system, this study is focused on the sensitivity of forecasts to individual observations for a typical DA configuration rather than optimizing or improving DA methods. Thus, we use the WRFDA 3DVAR system in its default configuration.

The three basic pieces of information required for DA are the first guess of the atmospheric state, observations and their associated error covariance matrix, and a background error covariance matrix. The first guess is obtained from a WRF cold-start analysis obtained with initial conditions from the most recent NAM forecast interpolated to the regional WRF grid in our study using the WRF Preprocessing System (WPS). Observations from the RAOB and MADIS are described above with associated errors for each platform included in WRFDA. The background error covariance method is obtained using the NMC method (Parrish and Derber 1992) applied to 60 24-h simulations from 14 March 2015 to 12 April 2015. Observations are initially rejected if the difference between the observation and first guess field is sufficiently large; however, this comparison is performed over three iterations such that if the updated analysis reduces the difference with a rejected observation it may ultimately be included. Each simulation is allowed three hours of "spin-up" time before the initialization time (Done et al. 2004). Depending on the demands of each simulation, data are assimilated throughout the spin-up time as described in the schematic in Fig. 7. For each simulation with MADIS data assimilation, observations are assimilated hourly for a three-h assimilation cycle. For simulations requiring the CLL RAOB to be assimilated, it is assimilated during the final hour of the spin-up time/ assimilation cycle (i.e., at the initialization time). Thus, for each case in our sample, all four simulations have a common initialization time, which is the time that the CLL RAOB is valid.

Objective verification of each forecast is done through comparison with Stage-IV precipitation data, MADIS observations, the Realtime Mesoscale Analysis (RTMA; De Pondeca et al. 2011), and the Rapid Refresh (RAP) operational model analysis, which replaced the

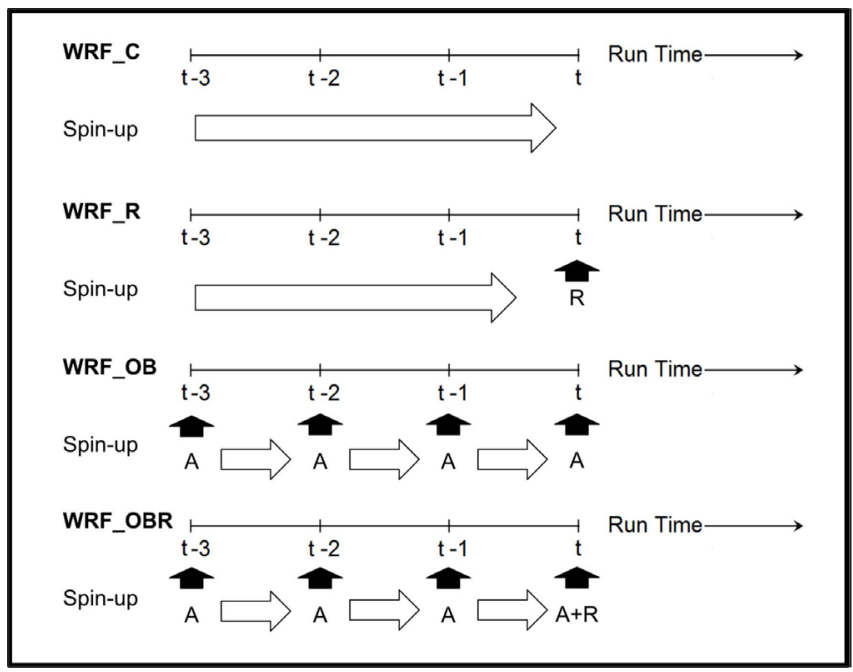

Figure 7. Data assimilation cycling strategies for each simulation. (A) represents when MADIS data are assimilated, and (R) represents when the CLL RAOB is assimilated. 
Rapid Update Cycle (RUC, Benjamin et al. 2004). Model Evaluation Tools (MET; Brown et al. 2009) from the Developmental Testbed Center (DTC) and SPoRTMET (Zavodsky et al. 2014) are used extensively in the model verification. Verification statistics including rootmean squared error (RMSE) and various skill scores [e.g., Critical Success Index (CSI), False Alarm Ratio (FAR), Probability of Detection (POD)] are computed for several variables of interest including temperature, moisture, and winds at both the surface and upper levels, and accumulated precipitation. Objective verification was also performed over two different domains: the full model domain, and a smaller domain surrounding and climatologically downstream of CLL (Fig. 6). Additional subjective forecast verification of simulated radar reflectivity fields is also included for a subset of cases.

\section{b. Analysis}

\section{1) Precipitation in convective cases}

For the small, downstream verification domain, the CSI, POD, and FAR for $1 \mathrm{~mm}$ of precipitation in the convective cases are relatively similar in all simulation runs (Fig. 8 a,c,e). The mean CSI and POD are higher for the first half of the simulation period for WRF_OB and WRF_OBR, suggesting a favorable early influence of assimilating MADIS observations, but they are not significantly higher than WRF_C or WRF_R when considering the large spread among cases. When the precipitation threshold is increased to $25 \mathrm{~mm}$, the simulations generally show less skill. The WRF_R simulation indicates meager skill improvements relative to the other simulations in CSI and POD (Fig. 8 b, d). From forecast h 4 (F04) to F19, all simulations have relatively similar CSI and POD, but from F19 to F22, CSI and POD for WRF R are higher than the other simulations, with mean skill scores occasionally a standard deviation above other simulations. Thus, there is some indication that radiosonde assimilation could improve the prediction of higher rainfall amounts at longer lead times. Though the FAR for the WRF_R simulation is generally lower than the other simulations during these hours, differences are less notable.

Although objective verification of the aggregated skill of simulations is helpful for diagnosing NWP benefit, subjective verification of an individual case can mimic how a forecaster might interpret a simulation. The case from 20 May 2011 shows improvement from

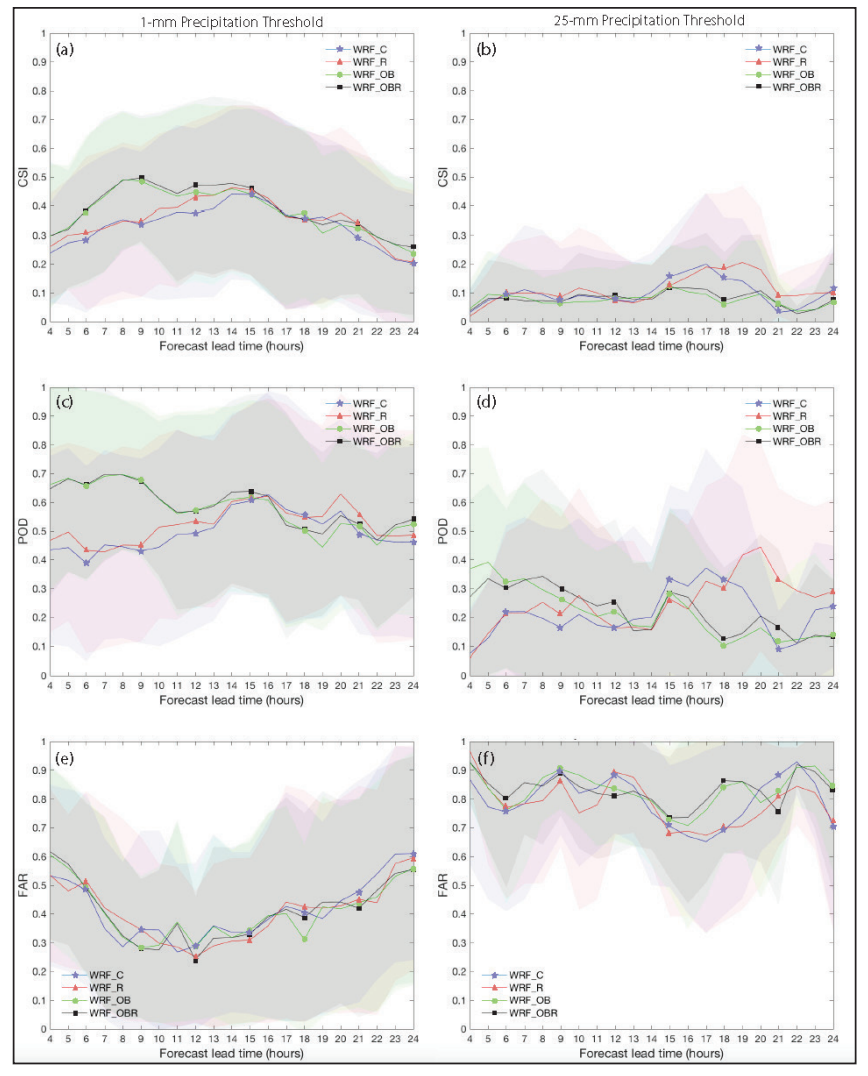

Figure 8. Time series of skill scores for hourly precipitation gridpoint neighborhood forecasts for each forecast hour in the small verification region. Average values for all convective cases for WRF_C (blue), WRF R (red), WRF OB (green), and WRF OBR (black) of $(\mathrm{a}, \mathrm{b})$ critical success index $(\mathrm{c}, \mathrm{d})$ probability of detection, and $(\mathrm{e}, \mathrm{f})$ false alarm ratio are shown for the $1-\mathrm{mm}$ and $25-\mathrm{mm}$ forecast thresholds, respectively. Colored shading indicates the first standard deviation of skill score values, with gray areas indicating overlap in skill between experiments.

the WRF R simulation in the CSI for $10 \mathrm{~mm}$ of rainfall (Fig. 9). Observed and simulated radar reflectivity at F12 (Fig. 10) demonstrate that the simulations with the RAOB assimilated, WRF_R and WRF_OBR, show forecast improvements in the reflectivity field relative to WRF_C or WRF_OB. For instance, while both WRF_C and WRF_R develop a strong bow-echo, the more northward placement of the precipitation in WRF $\mathrm{R}$ in east Texas and northwest Louisiana is more consistent with the location of observed precipitation at this time. Greater forecast improvement is seen when both the RAOB and MADIS observations are assimilated. While WRF OB shows two lines of convection near the Texas/Louisiana border, WRF 


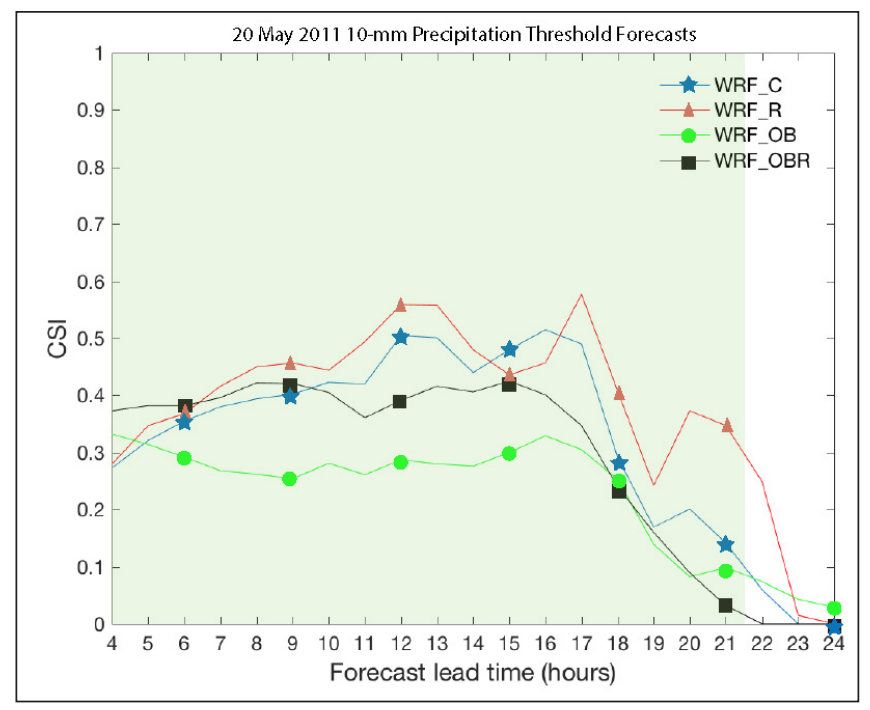

Figure 9. Similar to Figure 8, but for CSI for the 10-mm precipitation threshold only for the forecasts initialized at 1800 UTC on 20 May 2011. Green shading indicates the time period where precipitation was observed within the small verification region.

OBR shows one intense line of convection quite close to its observed position. Moreover, the addition of the MADIS observations improves the convective mode in Arkansas and northern Louisiana relative to WRF_C and WRF_R, with the most realistic forecast seen in WRF_OBR.

\section{2) Temperature in winter and convective cases}

Although precipitation forecast skill is not significantly different between the four simulations (in some cases, assimilation of observations slightly degrades CSI and POD scores), verification of 2-m temperature shows some improvement in RMSE for RAOB-assimilated winter cases when the verification domain is centered around and downstream of the RAOB launch location (Fig. 11). The WRF_OB and WRF_OBR have similarly low errors during the first $12 \mathrm{~h}$ of the forecast period relative to the non-MADIS simulations, suggesting that the additional RAOB assimilated in WRF_OBR provides little value when many other observations are assimilated. However, the WRF_R simulation shows considerable improvement over WRF_C during the first $12 \mathrm{~h}$, suggesting that the influence of the RAOB is more prominent when no other observations are assimilated. Figure 12 shows differences in temperature error of the four simulations at F06 as compared to the RTMA, including the benefit of assimilating the RAOB in WRF_R and WRF_OBR
(Fig. 12e, f). The benefit of the RAOB assimilation is more clearly seen without MADIS observations (Fig. 12e), especially in the vicinity of the RAOB location. Short-range temperature forecast benefits of the RAOB assimilation are also seen above the surface at $925 \mathrm{mb}$ (Fig. 13) for all winter simulations. WRF_R benefit was slightly higher than the WRF $\backslash \mathrm{OBR}$ benefit, but there are some small improvements from assimilating the RAOB in both cases.

Considering the tendency towards greater benefit from assimilating the RAOB without additional MADIS observations in the low-level temperatures at early forecast hours, we also investigated the duration of the impact at various height levels for both the winter

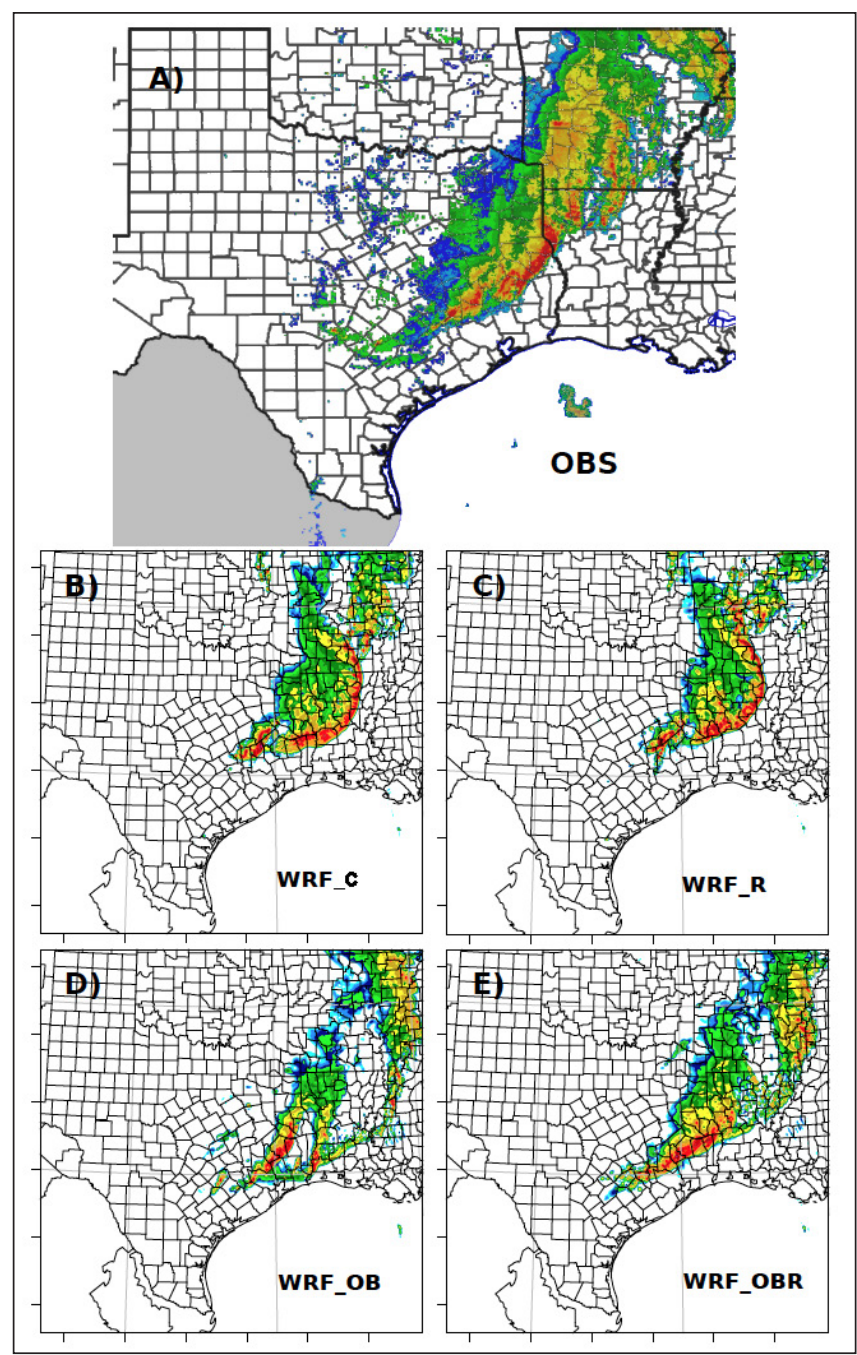

Figure 10. (a) Observed NEXRAD reflectivity mosaic and (b-e) simulated low-level reflectivity valid at 0600 UTC on 21 May 2011 (corresponding to forecast hour 12 in Fig. 6) for forecasts initialized at 1800 UTC on 20 May 2011. 


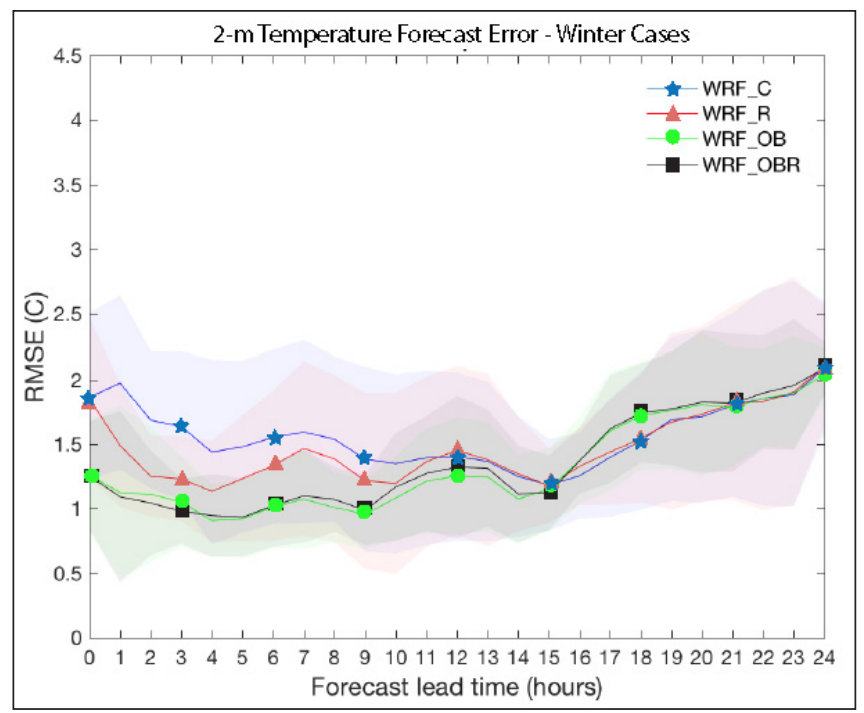

Figure 11. Time series of average root mean squared error $\left({ }^{\circ} \mathrm{C}\right)$ for 2 -m temperature forecasts in winter cases over the small verification domain. Standard deviations are shaded.

and convective cases when only assimilating the RAOB (WRF-R). Figure 14 shows the temperature benefit averaged for the winter cases, showing that there is a relatively strong, positive impact of the RAOB at low levels on the analysis for a large portion of the domain, centered on CLL. Some of this benefit appears to result in improved positioning of surface fronts in several cases, as can be seen particularly offshore in the 2-mi temperature benefit. With time, the lowlevel temperature benefit diminishes and eventually disappears by the end of the forecast period. The impact becomes more mixed aloft ( $850 \mathrm{mb}$ and $500 \mathrm{mb}$ ) where it quickly diminishes with time. Thus, the impacts on winter temperature forecasts are limited to low-levels and earlier forecast times. In the convective cases, there is comparatively much smaller impact from the RAOB assimilation on temperatures at all levels on the analysis (Fig. 15). The greatest benefit is confined to lower levels, where it tends to propagate towards the northeast (generally downstream for these cases) and rapidly diminish with time. Similar analyses were performed for both dewpoint temperature and wind speed (not shown), with generally negligible impact at all heights and levels, similar to that seen in Figure 15, regardless of the season.

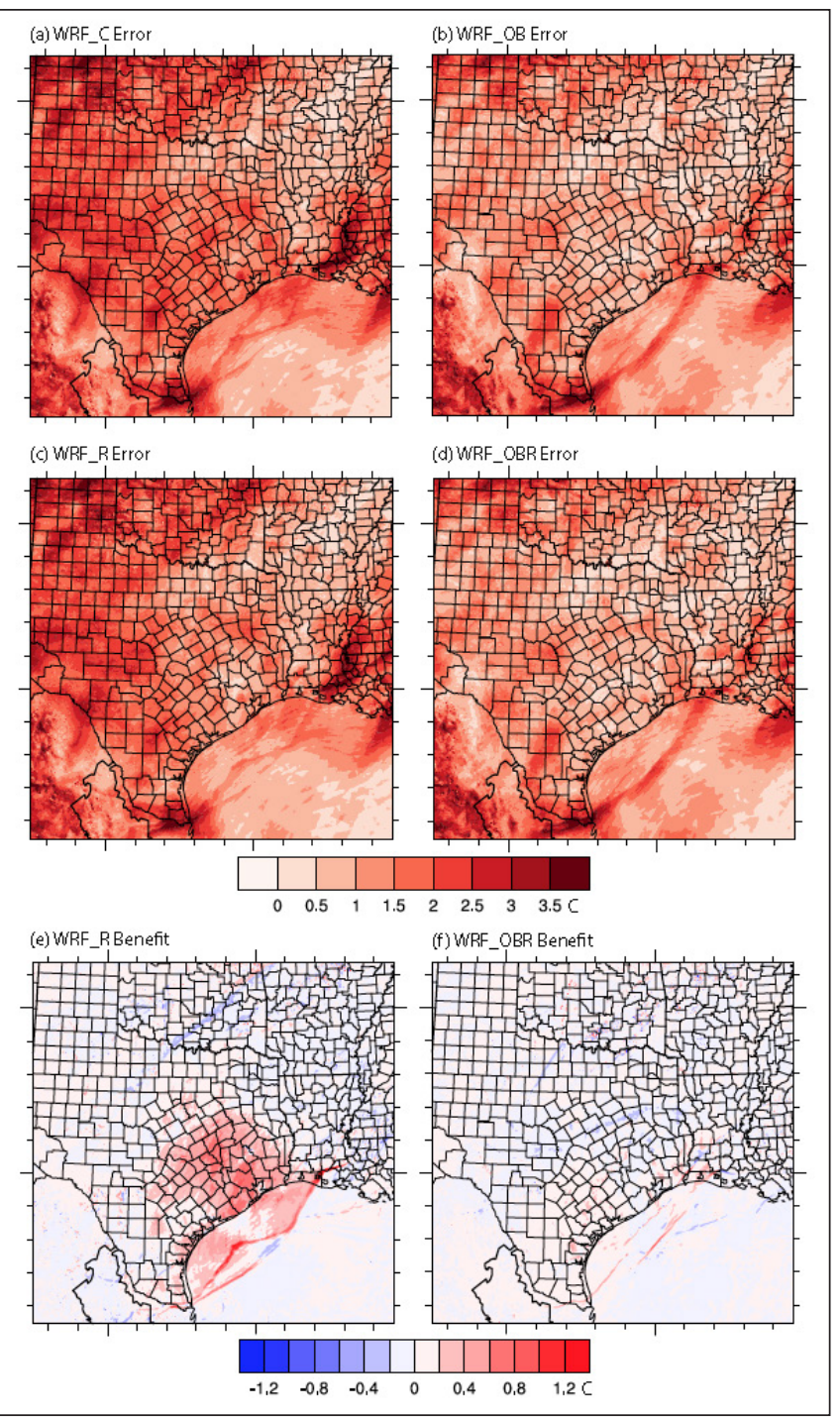

Figure 12. Absolute error $\left({ }^{\circ} \mathrm{C}\right)$ for (a) WRF_C, (b) WRF_OBR, (c) WRF_R, and (d) WRF_OBR simulations compared with the realtime mesoscale analysis for 2-m temperatures averaged over all winter cases at F06. The benefit $\left({ }^{\circ} \mathrm{C}\right)$ of radiosonde assimilation (defined as the absolute error without the RAOB minus the absolute error with the RAOB) is shown for (e) WRF_C - WRF_R and (f) WRF_OB - WRF_OBR. Positive (negative) values indicate forecast improvement (degradation) with inclusion of the RAOB.

\section{3) Effect of limiting MADIS observations}

For several convective cases, a different DA strategy was employed to test the sensitivity to poorer-quality MADIS observations. A large amount and variety of data types were assimilated for the 


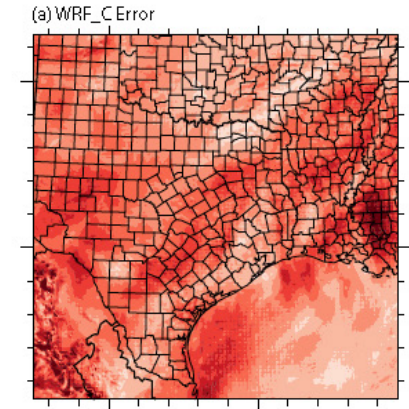

(c) WRF_RError
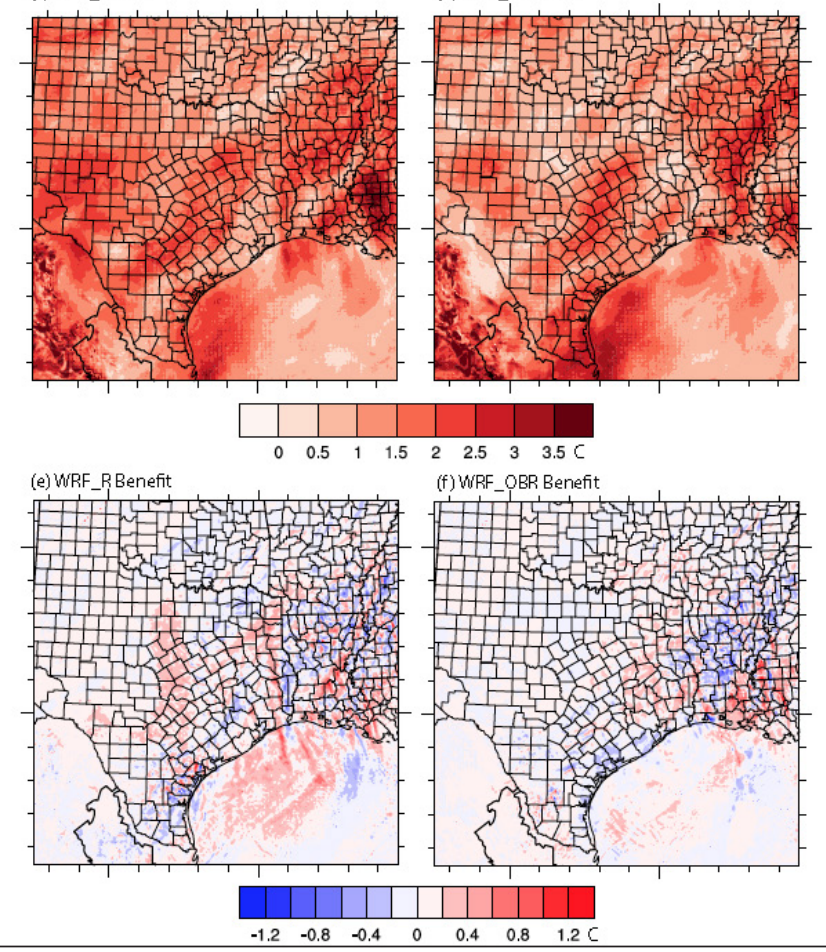

Figure 13. Similar to Fig. 12 but for $925-\mathrm{mb}$ temperature $\left({ }^{\circ} \mathrm{C}\right)$.

WRF_OB and WRF_OBR simulations, but the quality of the observations is not required to be of a certain threshold before assimilation. WRFDA eliminates some observations as part of its quality control, but some lowquality observations are still likely to be assimilated. Of the data types included in the previous simulations (described above), several data types were not included in the limited DA simulations. Mesonet observations, satellite observed winds, and profilers such as MAP and NPN were all excluded because some of these observations can be of lower quality. Figure 16 shows the impact of the limited DA for the 20 May 2011 case. The CSI and POD for WRF OB and WRF OBR are considerably higher for the limited DA (dashed lines) than for the standard DA, which suggests that poor quality observations were probably introduced into the

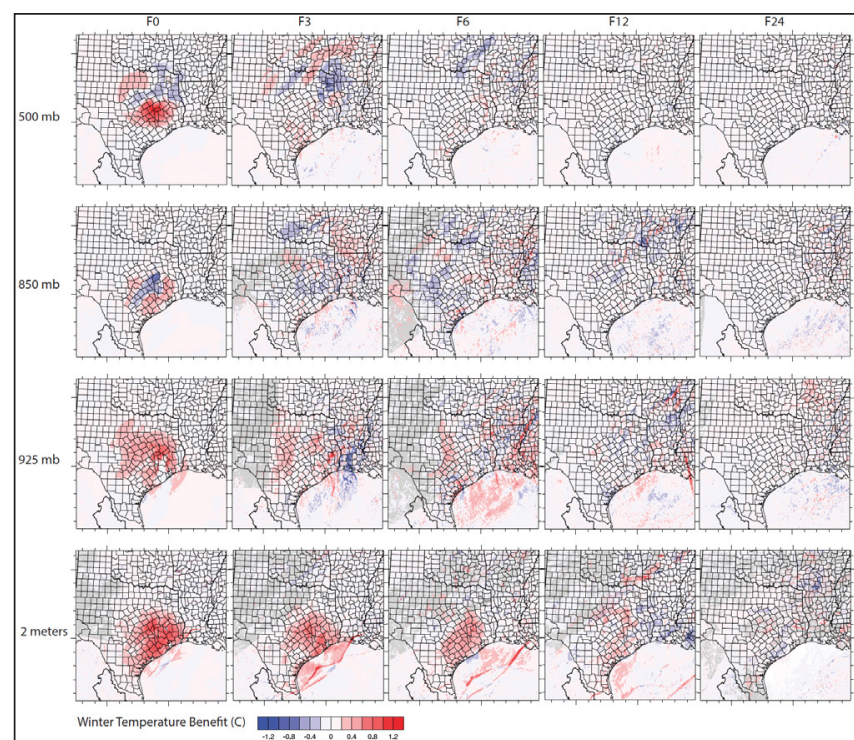

Figure 14. Similar to Fig. 12e,f but for the WRF_C WRF_R benefit $\left({ }^{\circ} \mathrm{C}\right)$ on winter temperatures at multiple levels and forecast hours.

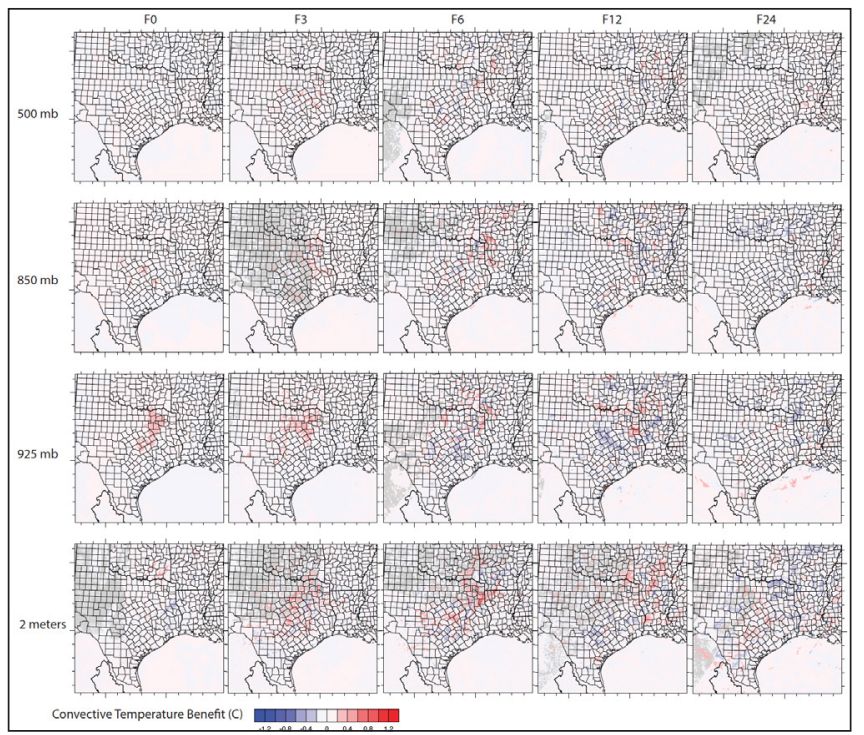

Figure 15. Similar to Fig. 13 but for the convective cases.

standard DA. In theory, every observation can improve a forecast, but only if its error is known and correctly processed by the DA system. Unfortunately, WRFDA does not currently have a procedure to assign different errors, such that poorer-quality observations are often weighted as heavily as more reliable observations.

\section{Conclusions}

A partnership program between university students at Texas A\&M University and operational forecasters 
to provide on-demand supplemental radiosonde observations in a data-sparse region has shown significant forecast impact to operational forecasters in both severe convective weather and winter precipitation scenarios. Experiments designed to test the sensitivity of convection-allowing model simulations to assimilation of the special RAOBs often show negligible influence of the RAOBs in high-resolution, regional NWP forecasts, but modest skill improvements are evident in some scenarios, particularly in forecasting low-level temperatures during winter precipitation events.

Overall, the model forecast improvements offered by assimilation of the radisonde are often insignificant for the cases simulated here. Indeed, the greatest forecast improvement often comes from assimilating MADIS observations (the differences between WRF_C and WRF_OB are typically greater than those seen between WRF_C and WRF_R or WRF_OB and WRF_OBR), so long as the MADIS observations are reliable. Introducing poor-quality observations may even degrade the model forecast relative to a "cold-start" simulation (e.g., Fig. 16). However, these results suggest the potential for improved skill during winter-weather scenarios. Lowlevel temperature forecasts in marginal scenarios that often occur in central and southeast Texas can make a large difference in precipitation type. Assimilation of the special RAOBs notably improves the model forecast of surface and low-level temperatures relative to a coldstart simulation, particularly for early forecast hours. As expected, impact of the RAOB is less evident when other observations are included in the assimilation. Even though we did not experiment with the data assimilation scheme, it is possible (or even likely) that other model and data assimilation schemes might yield more favorable results.

As radiosondes remain the backbone of both NWP and human analysis and forecasting for all types of weather, there is strong relevance to forecast problems such as severe convective weather, quantitative precipitation, and winter precipitation type. With total yearly costs of only a few thousand dollars, it is clear that an on-demand radiosonde capability in a data-sparse region can bring very cost-effective improvements to forecasting, particularly when the performing entity uses highly trained volunteers. Despite limited effects as an additional data point for assimilation in highresolution numerical model simulations, our experience shows that on-demand special soundings can be very useful to operational forecasters in a short-term forecast or now-casting setting. An academic institution with
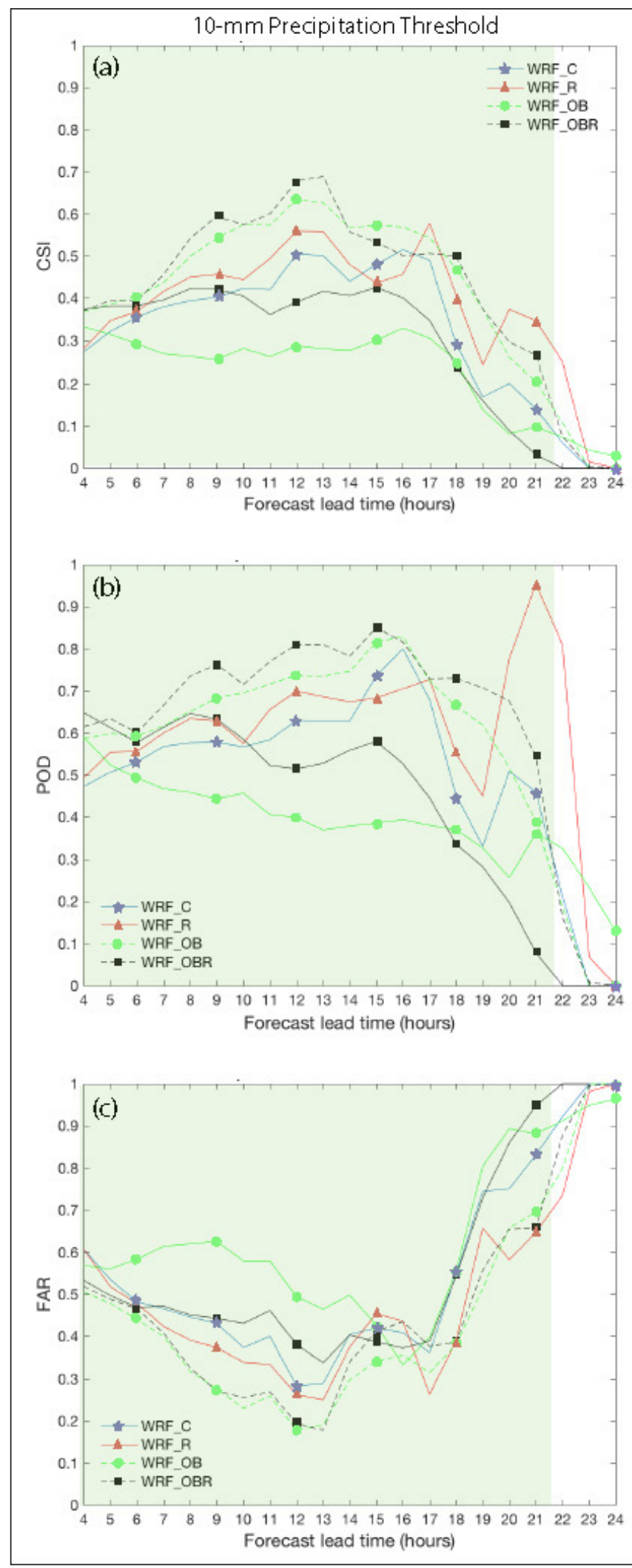

Figure 16. Similar to Fig. 8 but for only the $10-\mathrm{mm}$ precipitation threshold forecasts initialized at $18 \mathrm{Z}$ on 20 May 2011. Dashed lines indicate forecasts with limited MADIS data assimilation. 
a meteorology or atmospheric science program is an ideal situation in that the launches also hold tremendous educational value. Expertise developed through such programs also provides a pool of personnel to collect observations in future field experiments. Thus, as quality radiosonde equipment becomes more affordable and a greater number of universities explore high-impact learning experiences for their students, we hope the Student Operational Upper-air Program at Texas A\&M may serve as a model for similar partnerships across the country.

Acknowledgments: The SOUP program was funded by COMET Partners Project Z112-93224 and continuing support from the College of Geosciences at Texas A\&M University. We wish to thank all of the SOUP participants who collected RAOBs over the years of this study. We also wish to thank S. Corfidi, J. Zeitler for their comments regarding the usefulness of SOUP RAOBS, in addition to the many users of SOUP soundings for the continued support of the program. We also thank Drs. Istvan Szunyogh and Huilin Gao, who provided input on the numerical modeling experiments, which formed the basis of M. Benoit's M.S. thesis. Finally, comments from three anonymous reviewers improved the quality and clarity of this manuscript.

\section{REFERENCES}

Barker, D., and Co-authors, 2012: The Weather Research and Forecasting Model's community variational/ensemble data assimilation system: WRFDA. Bull. Amer. Meteor. Soc., 93, 831-843, CrossRef.

Benjamin, S. G., and Coauthors, 2004: An hourly assimilation-forecast cycle: The RUC. Mon. Wea. Rev., 132, 495-518, CrossRef.

, B. D. Jamison, W. R. Moninger, S. R. Sahm, B. E. Schwartz, and T. W. Schlatter, 2010: Relative shortrange forecast impact from aircraft, profiler, radiosonde, VAD, GPS-PW, METAR, and mesonet observations via the RUC hourly assimilation cycle. Mon. Wea. Rev., 138, 1319-1343, CrossRef.

Brown, G. B., J. H. Gotway, R. Bullock, E. Gilleland, T. Fowler, D. Ahijevych, and T. Jensen, 2009: The Model Evaluation Tools (MET): Community tools for forecast evaluation. Preprints, 25th Int. Conf. on Interactive Information and Processing Systems (IIPS) for Meteorology, Oceanography, and Hydrology, Amer. Meteor. Soc., Phoenix, AZ, CrossRef.
Chen, F., and J. Dudhia, 2001: Coupling an advanced land surface-hydrology model with the Penn State-NCAR MM5 modeling system. Part II: Preliminary model validation. Mon. Wea. Rev., 129, 587-604, CrossRef.

Coniglio, M. C., J. Correia Jr., P. T. Marsh, and F. Kong, 2013: Verification of convection-allowing WRF model forecasts of the planetary boundary layer using sounding observations. Wea. Forecasting, 28, 842-862, CrossRef.

De Pondeca, M. S., and Coauthors, 2011: The Real-Time Mesoscale Analysis at NOAA's National Centers for Environmental Prediction: Current status and development. Wea. Forecasting, 26, 593-612, CrossRef.

Done, J., C. A. Davis, and M. Weisman, 2004: The next generation of NWP: Explicit forecasts of convection using the Weather Research and Forecasting (WRF) Model. Atmos. Sci. Lett., 5, 110-117, CrossRef.

Ek, M. B., K. E. Mitchell, Y. Lin, E. Rogers, P. Grunmann, V. Koren, G. Gayno, and J. Tarpley, 2003: Implementation of Noah land surface model advances in the National Centers for Environmental Prediction operational mesoscale Eta model. J. Geophys. Res.: Atmos., 108, D22, 8851, CrossRef.

Gelaro, R., R. H. Langland, S. Pellerin, and R. Todling, 2010: The THORPEX observation impact intercomparison experiment. Mon. Wea. Rev., 138, 4009-4025, CrossRef.

Iacono, M. J., J. S. Delamere, E. J. Mlawer, M. W. Shephard, S. A. Clough, and W. D. Collins, 2008: Radiative forcing by long-lived greenhouse gases: Calculations with the AER radiative transfer models. J. Geophys. Res.: Atmos., 113, D13, CrossRef.

Inai, Y., F. Hasebe, K. Shimizu, and M. Fujiwara, 2009: Correction of radiosonde pressure and temperature measurements using simultaneous GPS height data. SOLA, 5, 109-112, CrossRef.

, M. Shiotani, M. Fujiwara, F. Hasebe, and H. Vömel, 2015: Altitude misestimation caused by the Vaisala RS80 pressure bias and its impact on meteorological profiles. Atmos. Meas. Techniques Discussions, 8, 21912222, CrossRef.

Kelly, G., J. Thépaut, R. Buizza, and C. Cardinali, 2007: The value of observations. I: Data denial experiments for the Atlantic and the Pacific. Quart. J. Royal Meteor. Soc., 133, 1803-1815, CrossRef.

Kerr, C. A., D. J. Stensrud, and X. Wang, 2017: Verification of convection-allowing model ensemble analyses of near-storm environments using MPEX upsonde observations. Mon. Wea. Rev., 145, 857-875, CrossRef.

Langland, R. H., 2005: Issues in targeted observing. Quart. $J$. Royal Meteor. Soc., 131, 3409-3425, CrossRef. 
Miller, P. A., M. F. Barth, and L. A. Benjamin, 2005: An update on MADIS observation ingest, integration, quality control, and distribution capabilities. Preprints, 21st Int. Conf. on Interactive Information and Processing Systems (IIPS) for Meteorology, Oceanography, and Hydrology, Amer. Meteor. Soc., San Diego, CA, CrossRef.

Nakanishi, M., and H. Niino, 2004: An improved MellorYamada level-3 model with condensation physics: Its design and verification. Boundary Layer Meteor., 112, 1-31, CrossRef. , and _ 2009: Development of an improved turbulence closure model for the atmospheric boundary layer. J. Meteor. Soc. Japan Ser. II, 87, 895-912, CrossRef.

Parrish, D. F., and J. C. Derber, 1992: The National Meteorological Center's spectral statistical-interpolation analysis system. Mon. Wea. Rev., 120, 1747-1763, CrossRef.

Skamarock, W., and Coauthors, 2008: A description of the advanced research WRF Version 3. NCAR Technical Note NCAR/TN-475+STR, National Center for Atmospheric Research, CrossRef.

Stauffer, R. M., G. A. Morris, A. M. Thompson, E. Joseph, and G. J. R. Coetzee, 2013: Propagation of radiosonde pressure sensor errors to ozonesonde measurements. Atmos. Meas. Techniques Discussions, 6, 7771-7810, CrossRef.

Thompson, G., P. R. Field, R. M. Rasmussen, and W. D. Hall, 2008: Explicit forecasts of winter precipitation using an improved bulk microphysics scheme. Part II: Implementation of a new snow parameterization. Mon. Wea. Rev., 136, 5095-5115, CrossRef.

Trapp, R. J., and J. M. Woznicki, 2017: Convectively induced stabilizations and subsequent recovery with supercell thunderstorms during the Mesoscale Predictability Experiment (MPEX). Mon. Wea. Rev., 145, 1739-1754, CrossRef.

, D. J. Stensrud, M. C. Coniglio, R. S. Schumacher, M. E. Baldwin, S. Waugh, and D. T. Conlee, 2016: Mobile radiosonde deployments during the Mesoscale Predictability Experiment (MPEX): Rapid and adaptive sampling of upscale convective feedbacks. Bull. Amer. Meteor. Soc., 97, 329-336, CrossRef.

Weisman, M. L., and co-authors, 2015: The Mesoscale Predictability Experiment (MPEX). Bull. Amer. Meteor. Soc., 96, 2127-2149, CrossRef.

Zavodsky, B., J. L. Case, J. H. Gotway, K. White, J. Medlin, L. Wood, and D. Radell, 2014: Development and implementation of dynamic scripts to support local model verification at National Weather Service weather forecast offices. National Aeronautics and Space Administration, CrossRef. 